\title{
Conceptual issues in institutional economics: clarifying the fluidity of rules
}

\author{
JAMIE MORGAN* \\ Research Fellow, Centre of Excellence in Global Governance Research, University of Helsinki \\ WENDY OLSEN \\ Senior lecturer, IDPM, University of Manchester
}

\begin{abstract}
This paper addresses the issue of how rules are conceptualized by Hodgson in Old Institutional Economics (OIE). The argument is put forward that the concept of rules can be constructively clarified. Rather than provide a general form of single rules within a rule system, we argue for a taxonomic range of single rule forms. This approach has the additional advantage of providing a more explicit account of how rules operate as part of a rule system. It also provides one way to address the fluidity of rules. Rules are understood to be more or less fluid (incomplete) and subject to a practical dynamism. This, we argue, can be differentiated from the idea of tendency based on the capacity of agents not to follow rules. A useful concept here is that of 'mezzo rules' or recodifications that both define the rule and distance the agent from their own rule-following behaviour. In pursuing the argument we also highlight various methodological implications. First, conceptual development is a key aspect of the OIE, particularly when it is located within Dow's structured pluralism. As such elaboration on rule forms enhances the consistency of OIE as methodology. Second, the exploration of a taxonomic range of rules and of forms of fluidity can provide useful resources in mapping out institutional processes in real research.
\end{abstract}

Geoffrey Hodgson has been a leading figure in the promotion of old institutional economics (OIE) in the UK in the last 20 years (e.g. Hodgson, 1988). That promotion has taken two related forms. First, the development and articulation of core concepts of OIE held to be applicable in a contemporary context. These are drawn in particular from Veblen and Veblen's intellectual resources, such as psychology, pragmatism, and Darwinism (Hodgson, 2001: chapter 10, 2004, 2007b). Second, Hodgson has maintained an ongoing project of analysis and dialogue with the New Institutional Economics (NIE) and mainstream economics in general (2007a). These two forms of promotion have been related in the sense that Hodgson sees new opportunities for the insights of the OIE to contribute to innovations that have been occurring within mainstream economics since the 1980s.

*Email: zen34405@zen.co.uk 
One of Hodgson's key insights has been that the OIE has a different metatheoretical perspective than that which has dominated the mainstream for much of the modern period (1998: 168-169, 173). Within the mainstream, general theory has primarily worked from sets of assumptions, sometimes as axioms, that closely determine the scope and content of models or specific theories and closely determine the identified specific mechanics of the particular economic phenomena that are studied. This has manifested itself within economics as disciplinary regulative processes regarding rigour and testability. In turn, these processes have created a primary focus on quantification and mathematical formalism in general (Hodgson, 2007a: 18-19). These processes in conjunction with broader changes within social science (behaviourism, positivism, new social policy demands for quantified solutions, etc.) marginalized OIE (2004: chapter 18). They helped to shape a mainstream landscape that was in addition, from Hodgson's point of view, and confirmed by other critics, insufficiently aware of the intellectual history of economics as a discipline, and insufficiently attentive to the significance of the broader training that leading economists from previous eras enjoyed (2001: 4, 2003, 2007a). By contrast, Hodgson wishes to promote OIE as a different kind of meta-theory. ${ }^{1}$ Rather than closely determine how what is studied is 'operationalized', OIE provides foci and insights based on its concepts that root economic activity in the generality of broader social reality. From an OIE perspective, this requires the study of economics to be pursued within an understanding of a more complex embeddedness of economy within social, cultural, and political milieus (e.g. Granovetter, 1985; Hodgson, 2007c).

For Hodgson, the OIE is a set of 'guidelines'. It is in this sense, in the context of mainstream understandings, that it became subject to the critique that it fails to provide a 'systematic' approach to economic theory (that it was 'anti-theoretical', Hodgson, 1998). Rather, OIE offers an open meta-theory of

1 Meta-theory is a problematic term because it can be interpreted in various ways. 'Meta' derives from the Greek and ranges in meaning from 'with' (genitive) to 'beyond' (accusative). There is a subtle distinction based on this range between an approach having a meta-theoretical perspective regarding other theories and being a meta-theory of substantive claims for a particular way of theorizing. As we set out in Section 1, the OIE has elements of both sides of this distinction, but does so in a non-contradictory way. As a set of 'guidelines', the OIE is a framework of inter-locking concepts. Adhering to this framework categorizes a particular piece of work within the OIE. That work has broad 'family membership' in Wittgenstein's sense of commonalities. Here the OIE can be thought of as being a meta-theory. At the same time, the OIE is critically engaged with alternative ways of theorizing and researching economy. Its framework of concepts provides openings and closures for that engagement. It was on this basis, for example, that Veblen constructed his devastating critique of neoclassical economics. And it is on this basis that one can view the OIE as an open theory of specific diversity - it is critically engaged and thus open to the possibility of change in its concepts, open to the possibility that other ways of studying economy are valid, but also commited to the idea that genuine engagement and critique entails that there is a limit to adequate accounts of economy. It is thus realist in ontological orientation, defined by its methodological orientation (institutions, rules, etc.) but not exclusionary in any a priori way. In functioning in this way, the OIE conforms more to an interpretation that it has a meta-theory perspective. 
specific diversity. It is, as such, the antithesis of an overriding concern with rigour to the detriment of relevance. ${ }^{2}$ The normative subtext of this meta-theoretical approach is that the economist should also be aware of the intellectual history of economics and also be a beneficiary of a broader intellectual schooling (beyond narrow technical proficiency, see also Heilbroner and Milberg, 1995). Hodgson sees scope for the expansion of the OIE because of internal critiques within the mainstream that have resulted in various innovations (NIE, experimental economics, behavioural economics, information-theoretic economics, etc.) that have reduced the dominance of the main manifestations of closely determining approaches (see also Maki, 1993: 3-4; Colander, 2000: 130). ${ }^{3}$

Our aim here is to provide a constructive contribution to the OIE as metatheory that articulates an applicable methodology of guidelines. We place the OIE within Dow's 'structural pluralist' account of economics as a discipline (Dow, 2004). Within this position the methodological position of the OIE as a framework of concepts that operate as guidelines requires that those concepts must themselves be open to the acquisition of more than simply content when they are taken up, reflected upon, and applied. Hodgson, for example, is actively committed to this in his dialogues with both heterodox and mainstream economists. Our contribution is to look again at the concept of a single rule within a rule system and to explore the way in which the concept of a single rule might be clarified through elaborations on its form. We argue that to make better sense of the way rules fit together as a rule system and to make better sense of the fluidity of rules, one can reasonably set out a taxonomic range of single rule forms and also conceptualize different ways in which rules are fluid. From our point of view, although the concept of a single rule as in circumstance $x$ do $y^{\prime}$ has the value of simplicity, it can be useful to expand the concept of a single rule and to differentiate between the capacity of an agent to only tend to follow a rule and the degree to which a rule itself allows for that tendency. We maintain that thinking about the taxonomic range of single rules and of the distinction regarding tendency is useful in creating a fuller set of guidelines in conducting institutional research on rule-following behaviour. With this in mind we explore the different ways in which the concept of rules can incorporate fluidity. That is, have a space or leeway built into them that then enables us to

2 For Hodgson, a main avenue for general theory to pursue is based on the limits of 'ontological unification' or the similarity of underlying structures and causal processes. In this sense, an OIE approach based on core concepts that allow for diversity of real manifestations is defensible as a meta-theory (Hodgson, 2001: chapter 1).

3 According to Hodgson 'economic theory has become fragmented into a number of technically driven specialisms and nothing has yet emerged to replace the consensus that prevailed from the 1950 s to the 1970s, mainstream economics has changed radically' (2007a: 11). The mainstream does, however remain relatively cohesive based on the perpetuation of problematic characteristics: formalism, the modelling of atomistic individuals, etc. In a sense, innovation within the mainstream has been constrained by the conditions of its own evolution (Neilsen and Morgan, 2005; Bourdieu and Wacquant, 1992: 118). On NIE and OIE, see also Dequech (2002). 
make sense of the real complexity of rules and rule systems. We consider this conceptual clarification and elaboration worth making in order to respond to the longstanding critique of Searle's work on rules: that it is 'unsociological' or difficult to apply to real processes and change, particularly in informal contexts. One important innovation we introduce here is that of mezzo rules. These are recodifications that both define a rule and distance the codifier from the rule as it is cognated. As such, mezzo rules are more than constitutive, they are a recognition that the individual is more than the agent within the rule form. We put forward the concept of mezzo rules as a useful way of linking fluidity within rules to the critical awareness of the agent that follows, breaks, bends, and transforms rules.

The argument is set out in three sections. In Section 1, we set out the core concepts and methodological implications of the OIE. This provides a context for the analysis in Section 2 where we look at some of the potential issues raised by thinking of single rules in terms of 'in circumstance $x$ do $y$ '. In Section 3, we then try to address the issues raised in Section 2 by considering the taxonomic range of single rule forms and the different ways we might conceptualize fluidity in rules and rules systems. This work forms the initial stage in a larger applied work in development economics. Unfortunately, space precludes any extended applications here.

\section{Core concepts and methodological implications of the OIE}

Hodgson identifies a broad group as contributors to the OIE. He identifies Veblen as its most significant originator from the late nineteenth century (up until Veblen's death in 1929). He identifies the inter-war years as its key period of influence on economics departments, following the 1918 launch of the 'institutional economics' movement spearheaded by John Maurice Clark, Walton Hamilton, and Wesley Mitchell. ${ }^{4} \mathrm{He}$ places Commons as a relative latecomer to this movement after 1929 and notes that, following the decline in interest in the OIE in the post-war years, the approach retained adherents and could also point to some prominent fellow travellers, including Galbraith, Myrdal, and Kuznets. ${ }^{5}$ From his reading of the work of this broad group of contributors to the OIE, and from his readings and engagements with philosophy, social theory, and Darwinism, Hodgson distils a series of definitions that provide an interlocking conceptual framework for an OIE approach.

4 Numerous histories of economics have been written and each has some purpose and remit in mind. Schumpeter's History of Economic Analysis (1997) is perhaps the most well known. The OIE is given relatively little attention in this vast work. Veblen and Henry George, for example, are categorized with a broader historical school. See also Parrish (1967).

5 The full list of contributors is far longer. See Hodgson (2001, 2004: xxii-iii). 
Institutions are defined as 'systems of established rules that structure social interactions' (Hodgson, 2006: 2). One of their key features is that they are durable, providing stability and consistency in social interaction. They are not, however, simply patterns of regular behaviour. Systems of established rules are embedded and persist beyond any given context in which they may or may not manifest in any given way. Each individual rule is understood to be a disposition or an injunction of the form 'in circumstance $x$ do $y$ ' (Hodgson, 2006: 3). The rule may be formal or informal, and may be applied consciously or unconsciously, but the rule is always potentially identifiable by a reflexive agent and is thus in principle codifiable.

The key conceptual problem Hodgson identifies with institutionalism is that a system of rules as an institution must be both a collective entity (a social object) encountered by the individual but also an internal guide for negotiating the complexity of an external social existence. As such, one must reconcile institutions as structures and individual action as rule-following behaviour. Following Veblen, for Hodgson the concept of habit provides the fulcrum between the external and the internal. Habituation is the psychological mechanism through which activity achieves embeddedness and expresses its institutional durability. Ways of doing and thinking become tendencies. This socialization may begin from the internalization of a formal rule system or from a looser form of immersion or exposure to an environment. In the former case habit is part of the way in which the institution takes on a practical reality. In the latter case, habit is already a constituent in that practical reality, but as a carrier of rules that can then in principle be codified as a formal expression of the institution.

Diversity and change are key aspects of the core concepts of OIE. Rules have normative content. Accordingly, habits as carriers of rules are also expressions of a normative dimension in social action. Here, the internalization of institutions through the fulcrum of habit shapes thought and practice because norms delimit a 'how' and a 'should'. Norms change, and thought and practice also change. One reason for this is the complexity of an institution as a real phenomenon. A person's positioning in terms of the institution is variable in a number of ways. Their location within sets of social relations can vary based on their role. The degree to which they are required to think about the rule system can vary based on that role. Relatedly, the manner in which interactions are pursued and outcomes are affective based on the rule system will vary. Moreover, individuals are more than social ciphers or reified roles. Individuals are not simply 'given'; nor does socialization create homogenous automatons. Personal psychology and development mean that some will reflect more on their otherwise habitual thought and practice than others. The manner of and degree to which rules are interpreted and valued is thus diverse.

Institutions, then, are real sites of diversity. Activity is tendential and the very basis of order is also the possibility of change. It is on this basis that both history 
and Darwinism are considered significant in OIE. ${ }^{6}$ It is on this basis that the OIE can appear to be lacking from a longstanding mainstream perspective. Its very call to relevance can seem antithetical to rigour because an otherwise economic institution and economic agent can be influenced by different social, cultural, and political elements. The approach, however, does not seem antithetical in terms of aspects of some innovations in the mainstream and within NIE. Hodgson, for example, identifies this in terms of recent developments in North's work (2007a: 14). Accordingly, Hodgson's approach to the OIE as meta-theory and to other theorizations from an OIE perspective has two implications for its place within understandings of methodology.

First, as a meta-theory framework of concepts forming highly generalized guidelines, the OIE is not prone to the exclusion of avenues of investigation in any a priori way. It is open rather than elisionary. Its guidelines, however, in so far as they are conceptual are more than simply an invitation to an undisciplined bricolage. Relevance must be established by plausible argument that establishes that an OIE framework for explanation and understanding has been produced and that this is rooted in evidence that explores unfolding processes in real economies. For Hodgson, and for Veblen before him, it is this focus on real economies that makes for an economic science of the real world. ${ }^{7}$

As a form of economics, the OIE demands clear accounts of a fuzzy world and is thus in accordance with the famous dictum usually attributed to Keynes: 'it is better to be roughly right than precisely wrong'. ${ }^{8}$ The meta-theoretical significance for how the social world is understood through the orientation of methodology is that the general concepts of OIE become 'economics' when they are applied to aspects of real world economies in an appropriate way. In essence, there is something specific about particular activity that gives substance to the research on that activity as economics rather than there is something particular about the initial theoretical concepts that then defines an economic domain. This is one of the great strengths of the OIE approach: it provides a more rooted

6 Specifically, history is the accumulation of institutions as forms of structures and within structures creating varieties of social emergence - a variety of evolution and selection (although as Hodgson points out the term selection is often misleading since it gives a sense of a guiding hand or telos that may not actually occur). Crucially, social processes have ordered principles but relatively unpredictable ongoing expression and change.

7 Veblen, of course, went further in suggesting that the economist like any other person was 'a creature of habits and propensities', and as such economics as knowledge and practice was a form of institution that could be critiqued in terms of its inertias (the dominance of hedonistic calculus, etc.) (Veblen in Lerner, 1948: 238).

8 This is particularly so when one considers Hodgson's summary of his view on the OIEs methodological commitments (1998: 173), and most notably: 1. OIE does not begin from a recourse to a model of rational utility maximizing agents. 2. Mathematical and statistical techniques are viewed as servants and not the essence of economics. 3. Analysis does not start by building mathematical models; it starts from stylized facts and theoretical conjectures concerning causal mechanisms. 4. Use is made of historical and comparative empirical material concerning real socio-economic institutions. 
continuity to social reality than more formalistic and axiomatic approaches to economics that give economies an 'other-worldly' appearance.

Second, the OIE meta-theoretical position that concepts are guidelines whose relevance is set according to real economies is one with ontological and epistemological implications. The OIE's meta-theoretical roots in early American pragmatism are particularly strong here. Peirce, for example, in rejecting early positivism and accepting that knowledge claims were contingent, sought to reconcile an objective world with a subjective process of inquiry, stating science could be defined 'not in the sense of stuffing it into an artificial pigeon-hole where it may be found again by some insignificant mark, but in the sense of characterizing it as a living historical entity' (Peirce, 1974: 19, 11.44$).{ }^{9}$ It follows from the OIE's intellectual resources that there are limits to the number of valid ways of investigating an economy. These are ultimately shaped by the interplay between developments in our theories and methods, what we want to know, what we want to influence and create, and how this is possible in terms of the already existing economy and the potentials inherent in the social reality towards which all this is directed. There are, therefore, two distinct but mutually engaged aspects to economics as a knowledge practice. Economics knowledge is fallible as a subjective product of theorization and investigation and economics knowledge is positional and purposive within a range of foci and normative standpoints. ${ }^{10}$ With these two aspects in mind, the OIE as meta-theory is one that is conducive to a vision of economics in terms of Dow's 'structured pluralism' (Dow, 2004: $\S \S 3-4)$. Moreover, it is one that is normatively committed to more than the coexistence of approaches. It is committed to progress through the resolution of mutual problems of theory, method, and conceptualization set by the ontological and epistemological limits that argument and research bring to the fore (Bigo and Negru, 2008).

The point we want to draw out here is that for the OIE to be consistent with its own meta-theoretical position as stated by Hodgson, its concepts, though guidelines, must themselves be open to the acquisition of more than simply content when they are taken up, reflected upon, and applied. They must also be open to constructive critique and clarification, adding both to our understanding

9 In addition to Peirce one might find similar points in Dewey. Dewey makes the link between the habitual nature of non-reflexive practice, philosophy properly understood as an ongoing engagement, and science as an open-ended process of enquiry, where philosophy and science have mutual critical roles in a progressive society (Dewey, 1920/1957). Notably modern pragmatism has diverged in its views on science, objectivity, and subjectivity. Richard Rorty, for example, is considered a modern pragmatist but is also highly subjectivist.

10 The concept of standpoints has been a difficult one for social science, particularly when related to the notion of epistemic privilege since this created problems of incommensurability between knowledge claims. It is notable, however, that many of the original standpoint theorists have rethought their views on objectivity, knowledge, and progress (e.g. Harding, 1993). 
of the concepts and of a specific aspect of economic activity. ${ }^{11}$ If this is not the case, then the economist cannot constructively move beyond 'the creature of habit' Veblen held the economist to be (Lerner, 1948: 238). ${ }^{12}$ Furthermore, the most persuasive methodological claim of the OIE, that it is an open theory of specific diversity, would come into question. Openness would be no more than a formal claim rather than an active practical commitment. One way in which constructive critique and clarification might be pursued is in terms of the status of single rules and in terms of their role within systems of rules as constituents in institutions. We argue that elaboration on rule forms enhances the consistency of OIE.

\section{Clarifications: single rules within the complexity of rules}

\section{The generative problem}

Hodgson defines an individual rule as a disposition or an injunction of the form 'in circumstance $x$ do $y$ '. This definition has the advantage of simplicity. However, the definition is stated as a 'general form' (for example, 1988: 185) rather than as a first step simplification and there can be a difference between the two. A simplification need not be a general form. It can be a single form of several forms that could also be specified as a taxonomic range. This is important because there is a great deal of ambiguity in terms of the concept of a single rule and the existence of a system of rules. One can make the analytical distinction between a single rule and a system of rules and this can be easily illustrated by naming a single rule as an example, but there remain practical problems.

There is an initial generative problem of how single rules of the general form 'in circumstance $x$ do $y$ ' act as a system of rules. There is always a danger of an overly literal approach to these single rules. This would give the impression that the general form simply aggregated to a system that functioned like a chain of basic algorithms or computer program of defaults. In circumstance $x$ do $y$, stop, in circumstance $a$ do $b$, stop, etc. This would be an inappropriate understanding

11 Note, the argument is not that fact masters theory, since this is always open to the problem of first concepts and Lockean tabula rasa, and it is always open to the problem of which aspects of reality are significant for which purposes of investigation (are the relations being explored contingent and/or ephemeral and underpinned by more durable elements?). Hodgson has some interesting things to say on the problem of levels of analysis, methodology, and abstraction (2001: chapter 21). See also Hodgson (1998: 173), where he discusses how there can be no fact without theory. The problem itself has also been a main current in debate concerning the role of ontology in economic theory and practice and has generated over a decade of comment and critique, much of it crystallized in Fullbrook (ed.) (2009).

12 There is a broad literature here regarding the sociology of knowledge that one might draw on. This ranges from the specifically anthropological approach to economics of Leijonhufvud (1973) to the theoretical complexity of Bourdieu's Homo Academicus in which he makes a plea for 'epistemological vigilance' in accordance with the goals of 'conscious neutralization of the probabilities of error which are inherent in a position' and the need to 'reveal the social foundations of the propensity to theorize and intellectualize' (Bourdieu, 1988: xiii). 
of the way rules fit together, given that rules are cross-referenced, tendential, interpretive (and diversely so), normatively cross-cut, and in constant inter-play with habit. ${ }^{13}$ It would lend itself to a rational choice and behaviouristic account (see Vanberg, 2007). It would be one in which the complexity, actual fuzziness,

and integrated nature of rules as real systems would be problematic. ${ }^{14}$ Clearly, Hodgson would not be sympathetic to a simple algorithmic approach of this kind to rules. ${ }^{15}$ As the above indicates, it would be antithetical to the very basis of OIE. Nonetheless, it is a potential problem deriving from the concept of a single rule, as is. If the concept is a guideline, in seeking this general form of rule would one be missing some aspects of the complexity of the institution as a system of rules?

\section{Searle on rules}

Part of the problem here begins with Searle's account of rules on which Hodgson draws (e.g. 2004: 14). Searle categorizes rules into two varieties (Searle, 1969: 33-38, 1995: 43-51, 1999: 122-124). Regulative rules influence antecedent or independently existing forms of behaviour - for example, the side of the road on which one should drive. Regulative rules have the general form 'if $y$ do $x$ '. Constitutive rules are basic elements that define a realm of social activity, making it what it is. Breaking them is usually taken to mean that one is failing to engage in that activity. The archetypal example is playing a formal game. One is either conforming to the rules of chess or one is not. For Searle, the general form of a constitutive rule is ' $x$ counts as $y$ in context $c$ '. The $y$ is the significance or meaning that is added to the act $x$ in context $c$ by the constitutive rule it embodies and by its place in the rule system. For example, when playing chess placing an unimpeded chess piece in alignment with the opposing king along a trajectory of the piece's allowed movement counts as 'check' (and this is chess that is being appropriately played). Constitutive rules operate through designating a status to the activity they define that brings something into existence.

Searle's account of rules was first put forward in Speech Acts in order to establish that language had a performative role. Following Austin (1961: 56-62), he sought to show how meaning and reference involved more than simply ostensive acts of simple object identification. Language did not just make truth claims about an independent material world. Language played a primary role in building an institutional world within a material world: a place of institutional facts. The mastery of a language is also the mastery of its rules or

13 Forming an 'emergent' institution. For Hodgson's take on emergence and emergent evolution, see Hodgson (2004).

14 Note there is a well-developed mainstream literature regarding rules and rule-following, but the focus here is the OIE. For mainstream discussion see, for example, Rabin (1993) and Lahno (2007).

15 Note there is a difference here between algorithmic approaches as a form of aggregated atomistic rules and Hodgson's generally positive account of the use of computer models of institutionalized cognition in exploring varieties of situated rationality in economics (Hodgson, 2004: 420-424). 
'linguistic characterizations'. Institutional facts (counts as $y$ ) could be produced by illocution as a rule governed act, for example marriage. In his later work, The Construction of Social Reality (1969), Searle generalizes this prior work on the philosophy of language to develop a philosophy of society. For Searle, social reality is the interplay between constitutive rules, a collective intentionality, or recognition that gives life to those rules as real institutions, and an individual intentionality through which agency engages those institutions through their assigned functions. Here, his original work on language and rules become part of a general solution to the agency-structure problem in social science (providing a continuous ontology of the material and social world). It is in this context that his work has had a clear appeal as a conceptual resource for OIE (see particularly Hodgson, 2004).

However, though Searle's work was a major step forward in our philosophical understanding of ordinary language, rules, and institutional facts, it has been widely critiqued (Rust, 2006). A main current of critique has been that it is a curiously unsociological account of society (e.g. Hollis, 1996). It was so to speak never 'operationalized' and the degree to which it could be so remained in doubt. ${ }^{16}$ One issue here is a starkness in the original definitions that stands in tension to the complexity of the manifestations of rules. This complexity takes two forms. First, as Searle notes, there is some degree of blurring between constitutive and regulative rules in any given instance, because any domain in which regulative rules operate likely includes some change in designated status based on constitutive rules that affects the situation. For example, driving on the wrong side of the road is liable to result in prosecution and might result in a criminal record. Second, there is some degree of blurring over the degree to which constitutive rules are descriptive (in virtue of designating status that brings something into existence) and the degree to which both individual constitutive and individual regulative rules operate within systems. Systems of rules frequently allow for choices that make sense in terms of the relation of the individual rule within the system of rules. A single constitutive rule describes what is done, but does not reflect the relation of that rule to the system of rules that constitute the individuated constitution. Moreover, neither the stated form of a constitutive nor regulative rule gives a sense of the relation of the rule to the possibility of choice between rules or within the rule, i.e. its relation to deliberative potential or processes. This is placed outside the rule form in the conduct of the agent. The rule forms as stated are ' $x$ counts as $y$ in context $c$ ', and 'if $y$ do $x$ ', combined by Hodgson as 'in circumstance $x$ do $y$ '. This parsimony invites elaboration in terms of operationalization since it must encompass how a single rule defines something as 'is' or 'done' in terms of an action as well as giving some sense of its relation to the choice of action or interpretation within

16 As Tuomela put it in an early symposium on The Construction of Social Reality, the different elements of the ontology are 'poorly integrated' (Tuomela, 1997: 435). 
the system in regard to further terms such as must, can, should, might, and so forth.

Interestingly, one might argue that heterodox economics has been a field that has actually contributed to showing how Searle's account of social reality might be applied and operationalized (Koepsell and Moss (eds.), 2003). For example, The Journal of Economic Methodology (2002, vol. 9.1) published a collection of papers with a focus on Searle (Boehm, 2002). Runde's paper in the collection is of particular note in the context of Hodgson's position on the OIE. Runde explores the relation between individual intention and rational choice models. Following Searle, he argues that individual intention occurs within Networks of intentional states (subject to the components of Searle's ontology of social reality previously stated) and against a Background of 'capacities, abilities, tendencies, habits, dispositions, taken for granted presuppositions and know-how generally' (2002: 16). This is in many respects similar to the way Hodgson argues from an OIE position that rational choice should be explained from the point of view of underlying habit rather than that rational choice accounts for an habitual practice as a rational routine (1998: 178). It also seems to show clear links to the relevance of conceptualizing particular empirical cases through the role of Polanyi's tacit knowledge (1962). ${ }^{17}$

One might, then, argue that there is a good fit between Searle's philosophy of society and the OIE that tends to support Hodgson's position on the OIE as a different kind of meta-theory. The emphasis on habituation in OIE and the commitment to relevance would seem to have something to contribute to Searle's work as well as drawing on that work. However, acknowledging this, either generally or in some specific way, such as acknowledging that habit plays a vital role in institutions, does not actually address the shared need of both for further clarification on the conceptual form(s) of individual rules within rule systems, i.e. the different ways in which rules might be stated or elaborated and the overall problem of how they are integrated. Background, context, intentionality, etc. are all important considerations. However, they all place the emphasis of elaboration outside of the rule form itself. A taxonomy of single rule forms might then be developed as a form of elaboration here.

Without that elaboration, the definitions of rules as is, which are found in both Hodgson and in Searle's work, function best as a heuristic aid in formal and fixed

17 The other main link here that is often forgotten when secondary sources on Polanyi have been used to appropriate his ideas is that Polanyi's purpose in Personal Knowledge was to reconstruct the concept of objectivity to show how objective knowledge of an independently existing world was possible. Personal Knowledge begins from a discussion of how scientific theories are both fallible historical products and acts of scientific progress. For Polanyi, the mediating point is the commitment of the individual intelligence to go beyond what is currently known. It is this that then leads him to explore the subjective circumstances of knowledge acquisition and its implications for how skills are developed and awareness from inarticulate problems becomes a focus for solutions. The lasting legacy of Polanyi's work has of course been the way it seems to blend aspects of habitual or recursive activity with rule-following. 
settings and, relatedly, in institutional research at higher levels of abstraction. This is because these areas have a relatively clear-cut sense of individual rule forms and a relatively coherent sense of the overall system within which rulefollowing and deliberation occur. However, the more complex and dynamic the system is taken to be, then the more important it becomes to express how single rules operate within a system of rules and the more important it becomes to express how rules themselves allow for issues like deliberation in different ways and to different degrees. Here, it is important to note that rules are not just transient, in the sense that they change through time, but that they can also be fluid, in the sense that they enable different degrees of latitude in their usage. ${ }^{18}$

\section{The fluidity of rules: practical dynamism and aporia}

Once one moves beyond formal games such as chess and institutions investigated at the higher levels of abstraction, one confronts the issue of the complexity, actual fuzziness, and integrated nature of rules as real systems. Rules and rule systems as parts of institutions are not just hazy because they involve habitual practice and are often not reflected upon, they can also be ambiguous in some sense because of what rules can be and the range of phenomena that rules can construct and influence. ${ }^{19}$ It would be a misinterpretation of constitutive rules to conceive of them as fixed. However, there is a tendency when thinking of rules as concepts to use them in a ceteris paribus way that tends to serve 'as if' they were fixed, creating a variety of conflation with the durability and embeddedness of the institution. ${ }^{20}$ This 'as if' is often convenient and perfectly acceptable from the point of view that it does not disguise that rules are temporally dynamic. It usually remains a relatively simple matter to acknowledge that rules, constitutive and regulative, are open for renegotiation and/or unintended transformation through time. Chess has evolved. What is money, how it can be used and what it can do (its institutional 'facticity') have likewise evolved (for example, broad money M4, etc.). Here, there is a certain sense in which the rules appear fixed at any one point in time and change through steps. 'In circumstance $x$ do $y$ ' seems fully adequate here because one can have a chain of such statements of specific altered rules through time. ${ }^{21}$ However, for the nature of social change to be fully

18 This, for example, creates interesting avenues for analytical explorations of the different ways in which different rule forms may be considered to be broken, misapplied, or creatively applied.

19 Perraton and Tarrant (2007) have looked at this in a slightly different way by assessing what it means to follow a rule that is in Polanyi's sense 'tacit'.

20 Note: the use of the term 'as if' here is not intended to be analogous to its usage in methodological argument, where it relates to ways to specifically and explicitly evade addressing the lack of reality of assumptions for theorization. This usage by Alchion, following Friedman, is as Blaug argues (1992), entirely unconvincing. The point here is that there are degrees of justifiable abstraction in OIE that leave some issues unelaborated because of the focus. Fleetwood makes an analogous point about how conceptual issues can be 'overlooked' (2008a: 185).

21 Although, as we show later, there are various ways in which it can be useful to explore the taxonomic range of rules and these are not restricted to exploring fluidity per se. 
apprehended, one must allow that rules and rule systems are not just transient, they can also be fluid in the sense that their form intrinsically resists closure, at any given time. The more fluid rules and rule systems are, then the greater the need to conceive of them in a way that resists this ceteris paribus and expands the way in which we conceive of rules. Here, one might want to think beyond 'in circumstance $x$ do $y$ '.

A useful way to begin to think beyond 'in circumstance $x$ do $y$ ' is to consider how rules have a practical dynamism or space built into their construction or application as well as a constitutive or regulative function. ${ }^{22}$ The practical dynamism is the degree to which a rule is currently fixed, or requiring a strict performance or conformity based upon its relation to the range of performances or illocutionary acts that might be made in its regard. The greater the variety, then the greater the practical dynamism that is built into the rule and the more fluid one might describe the rule. For example, in so far as rules can be conditional, they can be stated in ways where terms ranging from 'must' to 'should' and 'can' are internal to the single rule form. The actual initial form of the rule can thus have implications for the degree to which deliberation is formally entailed and the significance of any deliberation that then occurs. The same would apply to rule systems because rule systems themselves can have characteristics of this kind. There are interesting parallels here with the way Fleetwood attempts to clarify the role of deliberation by mediating between the work of Hodgson and Archer (Fleetwood, 2008a). Our point is that the rule itself can have a variety of forms that affect what is encountered by the agent and also what it means to be habituated. ${ }^{23}$ Fleetwood rightly notes that the concept of habituation is a valid solution to the problem of hyper-deliberation. At the same time, he contends that Hodgson's concept of reconstitutive downward causation can be extended to situations where the social-psychological mechanism in terms of a proximate cause can be one where intention is changed by deliberation (see Hodgson, 2002). As such, habit does not become irrelevant, but the relation between habit

22 The deliberative dynamic spans the real ambiguity of the two basic conditionals of rules stated in logic: the indicative conditional (where the fact of one statement rests on another fact) and the deontic conditional (an obligation or injunction is conditional on a truth stating sentence). Both can have the standard form if $P$ then $Q$ and be subject to modus ponens and modus tollens expressions. However, the ambiguity and openness of intent and context creates a variety of actual substantive forms of if $P$ then $Q$. Moreover, the if $P$ then $Q$ form itself creates the same basic problem for rule statements as 'in circumstance $x$ do y'. The conditionals are a popular form of the analysis of cognitive reasoning in evolutionary psychology. See for example Buller (2005: 174).

23 The concepts of habit and deliberation are, for example, usually distinguished. This is perfectly valid. At the same time, it creates problems since the habituation is relative. One can be habituated to certain types of analysis of given circumstances. As such, one is habituated to deliberate in given ways. This form of critique has, for example, been directed at Bourdieu's use of the concept of habitus - he is overly reductive regarding habit. As a way forward, a more mutable relation of habit and deliberation is intrinsic to Archer's taxonomy of ten different modes of reflexivity or different kinds of internal conversation based on empirical research. Here she rejects a 'hydraulic model' where individuals are passive recipients of constraints and enablements (Archer, 2007). 
and choice becomes more nuanced by different causal chains involving different degrees of reflexivity. Fleetwood's aim here is to preserve the uniqueness of the individual whilst recognizing the significance of their role as agents in relation to institutions and structures (see also Fleetwood, 2008b). We would contend that within an OIE perspective, extending the variety of the rule form also enables us to come to terms with the variety of conduct of the agent.

Here, practical dynamism might also be an indication of how a rule may be broken, bent, innovated, or transformed. The choice of action may become, for example, a genuinely creative response. One potential way to explore this might be in terms of the concept of aporia. Aporia refers to a state of being 'at a loss'. In philosophy, it is associated with an issue or situation placed in fundamental doubt by opposing positions. One might use the term, however, to refer to rule forms that are most fluid in that they invite creative responses because of the need to transcend the impasse created by the concatenation of single rule forms within a rule system - since there is no need to assume that a dynamic process of rules results in a coherent system at any one time. A rule system might be one that constructs contradictions in a way that invites counterfactual thinking and thus provokes particular forms of transformative deliberation because of the fluidity of the rules. For example, the recent global financial crisis has indicated several things about some single rule forms and the overall rule system in capital markets. First, different groups using different models of markets applied different single rule forms. Efficient market proponents had different rules of investing than those using technical analysis. Within both there was also a great deal of leeway since strategies and behaviour related to complexities that made the actual rule forms highly conditional (based on notions of degrees of efficiency, mathematics of arbitrage, time lines of complexity, etc.). At the same time, the emergent properties of capital markets deriving from actual outcomes in terms of particular events have highlighted a profound impasse regarding the broader rule system. Given the right conditions, all the behaviours within the system can have negative consequences (Morgan, 2009a, 2009b, 2009c). This has created a context for transformative deliberation regarding reform of capital markets focusing on issues of vulnerability and stability. Aporia has created a moment for genuine change, subject of course to social, cultural, and political factors in negotiating that change. ${ }^{24}$

One important point to keep in mind here is that though constitutive rules can be stated separately, comprehending a constitutive rule seems to require a comprehension of the environment the rules co-construct (the totality, as in a

24 Clearly, capital markets involve numerous rules of different varieties and degrees of formality, as well as a strong intersection between individual and collective strategies and behaviours and actual rules that influence and describe (but also evolve within and from) them. Any brief example may seem to conflate such variety, but in a sense the very danger of such conflation precisely illustrates the point rules are complex, variable and to varying degrees intrinsically fluid - they have a practical dynamism as rule forms. 
game, though reality is not a game). This, however, does not entail that the rule system always has one mastering position or definitive form fully apprehended and shared by all agents in the way some games do. The attention in the OIE to history, to a position in social relations, and to the psychological breadth of real agents is an important reminder of this. Constitutive rules can co-construct their own fluidity precisely because they can allow for leeway and multiple interpretations and valuations in activity. This is also the case for regulative rules. The degree to which this is so cannot be stated prior to an empirical investigation of the institution and its rule system(s). Thus, the OIE is rightly a meta-theory of guidelines to specific diversity. But for both reasons of consistency and empirical realism, the possibility of fluidity must be more than acknowledged. It must have implications for how we conceive of rules. ${ }^{25}$ The general point regarding fluidity is that it invites one to think of the formal concept of a rule in a way that is more consistent with the variability in rule-following behaviour. This, for example, has been a major issue in ethno-methodology where a great deal of debate has occurred over the relation between the indexicality of rules (their variable expression in context) and what a rule 'is' (e.g. Collin, 1997: 31). ${ }^{26}$

An important implication here is that it would be problematic to simply assume that reference to 'in circumstance $x$ ' or 'in context $c$ ' was sufficient to account for the fluidity of rules. If it were sufficient, this would entail that it was changed circumstances or contexts that accounted for changed actions as constituents in single rules. This, however, would create the impression that any given ' $d o y$ ' followed only from a single correlative circumstance or context. If 'circumstance $x$ ' did not change but 'do $y$ ' did, then one has a problem of identifying the rule. One might maintain that differentiating individual intention from the institution within which it occurs and then referring to background or to rules as tendential takes care of this problem. To a degree it does, since it allows that no single rule need always and everywhere be followed even in 'circumstance $x$ '. However, the acknowledgement points to the failure to follow any single given rule. It does not conceptualize the form that the rule not followed (or bent or innovated, etc.) might have in order for this to occur and in order for individual intention to be assimilated into the evolving institution. As such, the acknowledgement may well sensitize us to transience and perhaps to fluidity but does not fully capture it nor does it fully capture how the form of rules contributes to how rules are integrated. If rules are fluid in that they can, and

25 The point is equivocal since we do not wish to falsely claim that OIE has no sense of fluidity. Rather the issue for us is fluidity in the rule form. Veblen, for example, states: 'Changes are going forward constantly and incontinently in the institutional apparatus, the habitual scheme of rules and principles that regulate the community's life, and not least in the technological ways and means by which the life of the race and its state of culture are maintained' (1914/2006: 35). For a full view of Veblen's evolutionary naturalism, see, in addition to Hodgson, Tilman (2007).

26 Note: indexicality is not the same thing as index in Peirce's theory of language. For an excellent general account of Peirce's semiotics, see Nellhaus (1998). 
in many cases do, resist final closure, then this should also be reflected in the general forms by which the rules are stated. This clarification of ambiguity as ambiguity would be a contribution to clarity about a fuzzy world.

\section{Objections: Wittgenstein and the rule-following paradox}

Opening up the issue of fluidity in terms of how rules are initially stated can seem to create a new conceptual problem. It risks the counter-argument that fluidity can be pushed to a logical conclusion that puts into doubt the positive reasons for putting forth the need for a conceptual clarification in the first place. One might argue that a fluid rule is not a rule at all because fluidity allows that any activity could be in accordance with the 'rule' precisely because rules can be loose. Particularly in the case of instances of aporia, a rule becomes not a rule. Clearly, this is less of a problem when considering narrowly defined formal rule systems, and particularly matters of law and highly codified regulation. There may still be issues raised by codified discretion and matters of authorized interpretation relating to such systems, but convention might be said to wield a greater power of discipline within and upon them. ${ }^{27}$ Fluidity, however, would appear to be a bigger problem as the scope for practical dynamism, and particularly deliberative conduct, expands and as one thinks of the role of the range of individual rules within any complex institution, particularly in its informal aspects.

We would argue, however, that the problem is not one of the philosophical or practical impossibility of encompassing fluidity in the way that rules are conceived. The problem is actually one of coming to terms with the complexity of rules as expressed in both rule-following behaviour and in how rule-following is explored by the researcher. One useful way of illustrating this is the 'rulefollowing paradox' in Wittgenstein's later work. In Philosophical Investigations he states:

This was our paradox: no course of action could be determined by a rule, because every course of action can be made to accord with the rule. The answer was: if everything can be made out to accord with the rule, then it can also be made out to conflict with it. And so there would be neither accord nor conflict here. It can be seen that there is a misunderstanding here from the mere fact that in the course of our argument we give one interpretation after another; as if each one contented us at least for a moment, until we thought of yet another standing behind it ... 'obeying a rule' is a practice. And to think one is obeying a rule is not to obey a rule. $(1953 / 1997: 81, \S 201-2)$

This quotation needs some explanation. The basis of the paradox is twofold. First, observing a person's activity will not in itself provide an insight into a

27 For example, legal argument is confounded by case law and statute references to 'reasonable' 'accepted standard' 'due care and attention', etc. 
definite rule that is being followed. For example, if a person visits their elderly mother in a care home on Monday in week 1, Tuesday in week 2, and Wednesday in week 3, our intuition of a series may cause us to infer a rule that they will visit on Thursday in week 4 and so on. But the rule may be 'visit Monday to Wednesday on a 3 week cycle', 'visit on days when my mother is ill', 'visit on days that are set by care staff', 'visit on days that coincide with my own shift work', etc. ${ }^{28}$ Behaviour is an indication of no more than that rules may exist in so far as rules may be being followed. Second, a rule cannot be 'mentalistic' in the sense that it exists because it is thought. The nature of a rule is to have consequences. Thus, thinking a rule is not the same as 'to obey a rule'. The 'real' rule is the one that is used and the form(s) it is used in by a critical mass of agents to whom the rule is relevant.

Wittgenstein's point is not an ad absurdum critique of the possibility of rules or a sceptical refutation that rule-following can be identified by the researcher. Rather it is the important insight that there is no such thing as a self-interpreting or self-applying rule. This insight as he explores it in terms of the way we tend to conflate rules with abstractions (as prior mentalistic entities only) or with a series of observations that provokes an anticipated follow-on resonates strongly with common currents in contemporary OIE and with forms of realist methodology. For both Hodgson and realist methodology in general, it would be an actualistic ontological error to equate regularity with rule-following per se (Hodgson, 2006: 2; Lawson, 1997: 159-170). ${ }^{29}$ Further, it would be a methodological error to establish a correlation and consider this as sufficient in itself either to represent a relation or as a sufficient confirmation of a particular hypothesis of the basis of the correlation, in this case a rule (Pawson and Tilley, 1997: 117-121; Downward and Mearman, 2003: 119-122).

This may seem like going over old ground, but what Wittgenstein suggests in exploring the rule-following paradox is that rule-following is indicative of how we should appropriately think about rules. The essence of rules must incorporate their practicality. Rather like habit for Hodgson, the reality of rules has an internal-external dynamic (a nexus). Clarifying this ought to contribute to a fuller understanding of what it means in the OIE for humans as social beings to be constituted by their existence within institutions (e.g. Hodgson, 2006: 6-7). However, highlighting through the rule-following paradox that the essence of rules must incorporate practicality is perhaps all one would want to take from Wittgenstein on this matter since his overall approach to social reality in his later work contains numerous unreconciled tensions: he is inconsistent in his

28 Wittgenstein's most memorable illustrations are numeric or algebraic, for example Wittgenstein, (1953/1997: 74-77, §§183-190), Diamond (ed) (1976: 30). These, however, can give the impression that he was simply thinking about mathematical rules.

29 Though Hodgson has some longstanding criticisms of the work of contemporary realist social theorists and economists, he does also place his own work in the context of realism more broadly, particularly a realist reading of pragmatism (Hodgson, 2004: 215 and 404). 
use of the term regularity, he tends to eschew behaviouristic approaches but test concepts in quasi-behaviouristic terms, and he never really gets to grips with the gap between the materiality of reality and his focus on language games - all of which tends to create problems for how he seeks to resolve the implications of his work regarding rules. ${ }^{30}$

What we want to emphasize is that there need not be a philosophical hiatus when one recognizes that any action can appear to be in accordance with a rule. Rather it can be an invitation to accept the empirical and conceptual challenge that rules are in reality fluid to one degree or another. For example, one might consider the different ways in which fluidity might occur in regard of regulative and constitutive rules. Since constitutive rules designate status that brings something into being, the terms of usage and the basis of innovating, bending, and breaking of the rules through ongoing activity might be quite different than where regulative rules predominate.

In methodological terms, we take fluidity to be in accordance with Chick and Dow's (2005) approach to open systems. All systems have boundaries and connections; otherwise they would not be systems because they would lack some sense of unity or coherence. However, it is the conditions of any given system (the substance and strength of boundaries and inner connections and their

30 There are numerous examples of critiques of aspects of Wittgenstein's later work. The problem of behaviourism, for example, is addressed by Mundle(1971). Harre and Krausz (1996: 22) absolve Wittgenstein of intending philosophically indefensible forms of relativism but note that many others read Wittgenstein differently based on language games, materiality, and forms of life. Perhaps the most influential starting point on Wittgenstein is Kripke (1982). Kripke makes the case that Philosophical Investigations is an attempt to overthrow Wittgenstein's own approach to language in his previous work the Tractatus. The shift is from the truth conditions of language to assertibility conditions or justifications (1982: 74). This is not a denial of reality but of a foundational philosophy, since Wittgenstein's purpose in the rule-following paradox is to show that, if one looks for a given logically stated truth condition for a rule, one always ends up seeking a further rule in an infinite regress. The skeptical problem therefore requires a 'skeptical solution': meaning is to be found in the language game but also in its relation to natural responses that cannot be transposed into logic through philosophy. The solution can create particular problems or ambiguities about what it means to correctly follow a rule and what a social fact or status of a rule is since Wittgenstein $(1953 / 1997: 88, \S \S 241-242)$ seems to reject that human agreement dictates what is true or false, or that opinion (individual) is its arbiter - human agreement is in accordance with 'forms of life'. The status and meaning of consensus and practice in rule-following then becomes the issue. Kripke's reading of Wittgenstein is, however, one that might then be equated with Darwinism broadly stated, particularly if one considers social Darwinism. It is also in this context that one might best place Kripke's rejection of disposition as a solution to the initial regress (he is not rejecting that disposition occurs but rather that it is a philosophical answer). That I do respond to conditions in a way that might be described as a rule (in the anticipated series sense now stated as I am disposed to) does not explain why I responded in that way - the justification - and thus in terms of the original problem set up by Wittgenstein empties rules of meaning in order to provide an initial basis for their statement. In any case, disposition can be non-isomorphic with procedure and thus create problems for the understanding of rules in other ways - I may be able to dispositionally respond to $2+2$ but not $578+10,336$. Disposition does not, from this point of view, answer the skeptical observer. This is a quite different context of philosophical analysis than modern forms of realism, such as critical realism, or habituation in OIE, but is actually confronting the same problem of a complex material-social ontology as distinct from problems of epistemology. 
partiality) that define the degree to which it is relatively open or relatively closed and this is then expressed in its manifest consequences (and their frequency) through time. Systems exist in a spectrum. Similarly, rules as elements in rule systems and in institutions more broadly also exist in a spectrum of fluidity. This we would contend is more consistent with the OIEs approach to agency and structure where the individual, as an economic agent, is more than simply a social cipher or reified role, either a simple given or socialized homogenous automaton. The fluidity of rules helps to make sense of the notion of historicallysocially-culturally situated choice and deliberative conduct (including, for the economic agent, the concept of endogenous preferences that are also embedded in institutions).

\section{Coming to terms with fluidity}

Just as there is no difficulty in understanding that activity can have underlying causes but be tendential rather than mono-deterministic, there should be no difficulty in understanding that rules can be fluid. The challenge is: Can one state ambiguity or that things can be otherwise in a formal definition of a single rule? This is the conceptual problem that the issue of practical dynamics and of fluidity poses. The question, however, might be more fruitfully approached by first addressing the related question: Can one state a single rule as a general formal definition of individual rules within and composing a rule system? This brings us back to the issue highlighted at the beginning of the second section of our argument. Here we made the point that it might be more appropriate to consider single rules from the point of view of a taxonomic range. The range developed hereafter is intended to be illustrative of the potential of this way forward rather than to be in any sense complete. It is not a replacement for current approaches based on habit, tendency, background, etc., but rather an elaboration intended to enhance an OIE approach.

What we want to suggest is that thinking of rules as a conceptual taxonomic range serves two useful purposes. ${ }^{31}$ First, it fleshes out the concept of a single rule within a rule system to give a sense of the variety of ways that a rule becomes rule-following behaviour. Second, by doing so the range itself provides a bridge to how one might conceptualize the practical dynamism and fluidity of rules. As such, the range also provides a useful contribution to how the OIE approaches the way that rules fit together to become rule systems. The main innovation here is to think of the concept of the individual rule as also subject to mezzo-rules or further rules regarding rule-following.

31 For a different kind of analysis of the problems of rules within institutions, but one that acknowledges the issue of conceiving of change, see (Ostrom, 1986: 6). Note Ostrom develops something similar to the idea of a map to explore practical dynamism and describes this as an 'action situation'. 


\section{Forms of rules as a taxonomic range}

The simplest way of approaching the taxonomic range and the significance of mezzo-rules is to work through some possible single rule conceptualizations as progressive modifications from 'in circumstance $x$ do $y$ '.

'In circumstance $x$ do $y$ '

may be modified to become:

'In circumstance $x$ do not do $y$ '.

One might respond that the general form 'in circumstance $x$ do $y$ ' is still adequate because the modification may imply no more than that the rule followed was 'in circumstance $x$ do $z$ '. This could as easily be represented by the original in circumstance $x$ do $y$ ' since the alphabetical denotation is essentially arbitrary. However, this response would neglect various possibilities and it is the existence of the possibilities that indicate that the original concept would benefit from modifications that reflect the nuance that 'do $y$ ' conceals.

First, 'in circumstance $x$ do not do $y$ ' need not entail any action. There may be no $z$. The rule may be to do nothing. One might respond that $y$ can be 'nothing' and this is certainly the case. Thus 'in circumstance $x$ do $y$ (nothing)' might again appear to return us to the original concept. But there is still the case where 'in circumstance $x$ do not do $y$ ' holds because it is not doing the specifics of $y$ that is significant rather than the generality of doing nothing. 'Do $y$ ' where $y$ was nothing would not capture this. As such it would not capture the substantive bifurcation of rules based on social relations, such as differentiated gender or caste practices with economic and power consequences. These may be cases of prohibition or exclusion. The rule for Caste A may be 'in circumstance $x$ do $y$ ' and the rule for Caste B may be in 'circumstance $x$ do not do $y$ '. The 'nothing' only makes sense in terms of the specification of $y$ and this in turn only makes sense in terms of the single rule within the rule system having the general form 'in circumstance $x$ do not do $y$ '. Here, failing to adequately set out the single rule form would create problems for comprehending the way the rule system was constituted in terms of and expressed through its individual rules as cross-referenced processes. One might say that reflecting the distributive effects of power also entails a distribution of single rule forms to express the way power is manifest through the rule system.

Second, in addition to the absence of any $z$, it is conceivable that $z$ may be significant within the rule, but not be directly substitutable for $y$. It may be that one can only adequately capture the rule form by stating 'in circumstance $x d o$ not do $y$, do $z$ '. This may be for a variety of reasons. For example, one might reformulate the do nothing of the previous 'in circumstance $x$ do not do $y$ ' as 'in circumstance $x$ do not do $y$, do $z$ (nothing)' since the nothing is a substantive imperative rather than some inconsequential residue. This addition may of course be deemed trivial. However, it becomes less trivial the more substantive and 
significant 'do $z$ ' becomes in relation to $y$. These are instances of 'in circumstance $x$ do not do $y$, do $z$ (something)'. A simple example that does not immediately involve the power issues of the previous example is that of the development of sell-by dates and use-by dates and their role in perishable food consumption conventions. Thus one might have the specific form: 'when bagged salad passes its use-by-date, do not eat the salad, throw it away'. The 'do not eat' may appear trivial, but it is the fulcrum for 'throw it away'. It is only by reflecting upon 'do not eat, throw it away' and the normative commitments that are engrained in the entirety of the rule form as a convention that has become habit in many advanced economies that one can build up a critical analysis of the current endogenous preferences that are creating the problem of waste. Understanding waste begins from the significance of 'do not eat' and its relation to 'throw it away'.

One can also return to the example of caste and consider instances where the rule is not based on simple prohibition or exclusion, but the alliance of such with specific imposed practices. Thinking about how caste practices are cross-referenced and distributional is a useful lead into noting that single rule forms reflect different characteristics. For example, comparing the consumption and caste examples one might note that the rule form 'in circumstance $x d o$ $n o t$ do $y$, do $z$ ' does not in itself give any indication about the pervasiveness or common applicability of the rule for agents in regard of 'circumstance $x$ '. The significance of cross-referencing would only be formally expressed in the concept by adding agents as significant elements within the rule form. One might have for example: ${ }^{32}$

'In circumstance $x$ do not do $y$, do $z$ whilst a does $y$ ' (a non-specific time relation rule).

'In circumstance $x$ do not do $y$, do $z$ if a does $y$ ' (a conditional potentially correlative relational rule).

'In circumstance $x$ do not do $y$, do $z$ because a does $y$ ' (an explanatory but conditional relational rule).

This kind of iteration can quickly begin to appear like a game theory map of tactics and strategy. In so far as it does so, such a map can give the impression that rules are simply a reductive aspect of atomistic individual behaviours. This would give the impression that cross-referencing as expressed in rules was not genuinely relational. As such, it might seem purely intra-subjective, i.e. concerned with tacitly autonomous disembodied and timeless given entities. This, in turn, and as Fullbrook (2004) has argued, would reproduce the problems of homo economicus, following Walras and in contrast to Smith, which are so deeply

32 Equally one might pursue 'In circumstance $x$ do $z$ whilst a does $y$ ' (a non-specific time relation rule), etc. Not also that ' $i f$ ', 'whilst', 'because' are not mutually exclusive, they are rather indicative of the key element of the rule form relation that the researcher finds descriptively appropriate. 
engrained in thinking in economics. ${ }^{33}$ That, however, is not the intention. The intention here is to bring out the different ways in which rules occur. Rules themselves are to be understood as an expressive aspect of the inter-subjectivity of reality. The being of subjects is inter-dependent and one aspect of that being is precisely the way that rules occur. Once specified, such rules are no more or less guidelines than the original 'in circumstance $x$ do $y$ ' found in OIE. Here, the introduction of a taxonomic range is not an alternative to the concept of habit within OIE, it is about what kinds of rules are being followed and about different levers in any potential codification. As such, the range provides the researcher with a conceptual resource. The existence of that resource is not an invitation to simply construct an abstract model of interactions. Rather the aim is to pursue the significance of the variability of rules in real situations. For example, qualitative research might focus strongly on the do not element of various rules. This ' $d o$ not' may be entirely latent (a curious habituated silence or block or 'internal exile') for the agent in an otherwise consciously followed rule of do $z$. The agent may be thinking of the rule as 'in circumstance $x$ do $z$ ' and it may be the researcher who highlights the significance of 'do not do $y$ '. This creates interesting issues for how one then thinks about conceptualizing rules in regard to habit as understood in OIE. In OIE, rules are always potentially codifiable, but one now has the issue that the rule may already be codified in one way by the agent but may then be recodified by the researcher based on the interaction of habit and rules for the agent. This is an additional way of approaching typical agent-structure interactions and the problem of 'hermeneutics'.

Methodologically speaking, the modifications so far of the original single rule form are important because they express different characteristics of rulefollowing behaviour, providing different emphases. One of the things they allow us to do is differentiate between multiplicity of single rule forms and choice as rule-following behaviour. Circumstance $x$ may be common to all agents and what is done may be highly variable because numerous single rule forms follow, particularly for different groups or agents. Each rule, however, may be highly regular in its application. One simple way to address this is to include a further modification of the rule form in terms of the scope of doing. For example:

'In circumstance $x$ do not do $y$, do $z_{1} \ldots z_{n}$ ',

Again, the formal concept of a single rule begins to look purely algorithmic. ${ }^{34}$ This is particularly so when one thinks of possible further combinations of

33 This is a point also made by Alison Assiter regarding political theory in ways that intersect with much of Fullbrook's concern with the genealogy of intra and inter-subjectivity (Descartes and onwards). See Assiter (2009), particularly chapter 1 regarding classical liberalism.

34 Note, we do not intend to imply here that there can be no valid mathematical applications in economics. We simply want to suggest that the construction of abstract models in isolation is not the purpose of our analysis of rule forms. There are, for example, interesting applications of fuzzy logic here. The fuzzy logic is trying to allow for an asymmetry between $x$ and not- $x$ such that a case can be fuzzily 'in' $x$ and fuzzily 'in' not- $x$ at the same time. Possible paradoxes are enumerated by Bergmann (2008). 
rule forms based on prohibitions, impositions, varying agents, and degrees of choice. Here, one can quickly appear to be surrendering conceptual simplicity for an untidy complexity. However, if one were to think of the initial rule forms (those stated here and any others that might be reasonably conceived) as elements in real research where they are used to construct a schematic or map of actual rule-following behaviours, the importance of the modifications should now begin to be apparent. Many similar approaches have been undertaken in experimental economics. ${ }^{35}$ What we want to emphasize is that the taxonomic range is indicative of the complexity of rule-following behaviour. It provides a means to show how rules might fit together to work as a system. For example, they may fit together through the distributional characteristics of rules when cross-referenced. In terms of applying an OIE approach, this is a particularly useful exercise when thinking about informal rule systems within institutions.

Mapping on the basis of the taxonomic range set out so far would give some indication of the practicality or active status of rules as real rules. It also allows, when the mapping is diachronic, for forms of change to be tracked, indicating a kind of fluidity of rule systems based on the complexity of the interactions of individual rule forms. This is a particularly useful method for looking at unintended consequences. Moreover, one can use the limits of this taxonomic range as a useful device in thinking about the further characteristics of rules and rule systems in terms of the significance of inter-subjectivity. We have indicated that multiplicity is different than choice. It is also the case that choice can be of different kinds, and thinking about this can bring us closer to a fuller concept of fluidity expressed in the rule form.

\section{Fluidity: mechanistic choice, deliberation and mezzo rules}

It is possible to define a given choice or received choice set as part of a rule as we have done in the previous section. In this regard, the use of algebraic notations such as $z_{1} \ldots z_{n}$ are familiar in many branches of economics. However, the focus on formulations such as $d o z_{1} \ldots z_{n}$ does not in itself fully capture the concept of choice in rules precisely because it is a predefined configuration or choice set following on in 'circumstance $x$ '. It appears less deterministic than $d o z$ but it is in many ways the same form more complexly stated. This has interesting implications for Chick and Dow's definition of an open system. They argue that it is the conditions of a system rather than its outcomes per se that are significant for defining its degrees of openness or closure (2005). We would add the further caveat that within the conditions one must be careful to assess the characteristics of areas of choice since a system may appear to be irregular in outcome $\left(z_{1} \ldots z_{n}\right)$ and in condition (the full rule form $d_{o} z_{1} \ldots z_{n}$ ) and yet be one that is relatively fixed or fixing of the present from the past. We would note that one must also allow for the choice to do otherwise than the choice set $z_{1} \ldots z_{n}$, i.e. to refuse the

35 Though the degree of abstraction and understandings of rule-following behaviour can be highly variable in this work, see Santos (2009). 
rule or to be creative in its regard (perhaps based on situations of aporia). One can express this by differentiating:

'In circumstance $x$ choose between doing $z_{1} \ldots z_{n}$ '

and

'In circumstance $x$ tend to do $z_{1} \ldots z_{n}$ '.

Of course, in terms of the single rule form concept one might argue that the $z$ of $d o$ $z$ or one of $d o z_{1} \ldots z_{n}$ (or the same of $y$ ) may be 'do something new/unexpected' and as such the rule form may be other than deterministic. It remains the case, however, that the formulation invites us to think deterministically once the rule is in play even where some degree of 'choice' is introduced. The form of choice represented in the concept of rules is one that we are likely to think of as mechanistic. It is, therefore, worth differentiating within the rule form between 'choose between' and 'tend'. This is because doing so highlights that there can be a distinction between the latitude within a rule and the capacity of an agent to refuse or reject a given rule. Rule-following remains consistent within an OIE perspective as a tendential activity of agents, but the distinction differentiates between the capacity of the agent and the rule form as the condition within which that capacity occurs. The distinction is one useful way of thinking about fluidity within rules. The distinction is also a useful one in conducting institutional research because it allows one to highlight the degree of constraint (perhaps distributions of power) built into rule forms. Furthermore, the distinction is also useful in our broad understanding of the concept of rules because it reconciles a potential inconsistency in how we understand breaking rules. The distinction helps clarify some aspects of transgressing norms and laws. Many laws and norms that are core aspects of economic activity are of the form 'In circumstance $x$ choose between doing $z_{1} \ldots z_{n}$ '. If as an agent one tends not to follow them, then they are broken. However, rules of the form 'In circumstance $x$ tend to do $z_{1} \ldots z_{n}$ ' may be better thought of as bent than broken when an agent exercises her capacities to go beyond them (based on the individual capacity of agents to tend only to follow rules).

Thinking about the difference between 'choose between' and 'tends' may also give some indication of the difficulty of changing a given rule and rule system. It may, for example, be that a 'choose between' rule form slowly degrades into a 'tends' and as such becomes increasingly subject to being bent and ultimately transformed. Here we can think about another aspect of fluidity. As noted, one of the main identified problems with Searle's work on rule forms is that it is 'unsociological'. More broadly, it is under-elaborated in terms of its conception of change. One might, for example, make the point that the approach it fosters is one that seems to be restricted to preconfigurations (choice sets). So far we have suggested that the concept of rules and the idea of practical dynamism or fluidity in and through rules might be approached in terms of how individual rules fit 
together and in terms of how different individual rule forms can be more or less deterministic even when involving choice. But one might also consider the idea of fluidity in terms of its relation to deliberation as it impinges on the rule form that is then codified.

The key question here is how does one conceptualize the codified rule where there is an interpretation of the rule and a degree of deliberation. As Hodgson puts it: 'How do people understand and follow rules? We have to explain not only the incentives and disincentives involved, but how people interpret and value them' (2004: 425). In both the OIE and Searle's work, the general rule is left in a convenient simplified form, for example in circumstance $x$ do $y$ ' because the intentional active agent (within and through collective agency effects or recognition) is considered sufficient for an understanding of the issue. ${ }^{36}$ However, we have been at pains to show that the fluidity of rules must be accounted for in the form of the rules. Rules must be in some sense fluid. Otherwise there is a potential disjuncture. One might think of that disjuncture in terms of analogous statements such as 'a fixed rule that is sometimes followed', 'a gene that allows us to ignore our genes', or 'all Cretans are liars, said the Cretan'.

One potential way forward here is to look again at the descriptive or status designation aspect of a rule and its relation to deliberative conduct within the rule system (Ransdell, 1971; Ruben, 1997). Clearly, the constitutive aspect of rules defines the terms of any conduct by creating a context for recognition (even if recognition is subliminal and action is habitual). However, if we think of this constitutional element, it is not just about doing, it is about being. This is inherent in both Searle and Hodgson's approach and is thus not a wholly original point. But it is one we can clarify and bring to the fore by stating it in the rule form more explicitly in order to make sense of interpretation and the valuing of rules. Any individual rule may entail degrees of choice and may apply to some agents (positioned in some ways) but not others. In so far as when that rule is (as it usually is) habituated it is always subject to potential subsequent codification, it follows that all forms of rules allow for varieties of interpretation. Here, one can be simply asking oneself in terms of circumstance $x$ what is $y$ or $z$ or $z_{1} \ldots z_{n}$ that one then does. This is interpretation as simple conscious recognition of the original rule form and (perhaps) the degrees of choice it enables. However, the act of codification or of recodification is also more broadly a question of being. Here Searle's constitutive form ' $x$ counts as $y$ in $c$ ', or Hodgson's 'in circumstance $x$ do $y$,' can be usefully rephrased as:

'In circumstance $x$ be $y$ that does $z$.'

This kind of codification enables the agent to recognize the difference between their institutional location and the role they are undertaking and the act of

36 And as Hodgson persuasively argues, the accumulation of history and the denial of the significance of some original state are also important considerations (as well as key critiques of NIE). 
rule-following itself. As such, it is implicit in a sense of self as an individual able to recognize that she is not reduced to any given role within and through an institution. At the same time, it is a recognition that identity is in some sense shaped by that institution. The very nature of inter-subjectivity is thus highlighted and brought into question. What is my role in a nexus of inter-dependencies? This may seem to recreate the problematic of intra-subjectivity, but can more sympathetically be understood as the unstable dynamics inherent in the question: In what sense do specific processes seek to make me in terms of you, I and we? ${ }^{37}$

The point may seem rather abstruse. But the idea of codification or recodification is rather simple. Rule forms can express a distancing and as such invoke critical awareness in terms of inter-subjectivity. This can extend from highly generalized situations such as 'be a consumer' to highly specific ones such as 'be Tiwari's tenant'. This kind of codification is one that sits beside the way habit links the inside and outside of institutions. The codification links the capacity of human agents to only tend to follow rules and the individual rule form 'In circumstance $x$ tend to do $z_{1} \ldots z_{n}$ '. It might be thought of as an expression or codification that implies a deliberative process that then perhaps begins the degrading of rules that were previously of the form 'In circumstance $x$ choose between doing $z_{1} \ldots z_{n}$, ${ }^{38}$ As such, we might designate 'In circumstance $x$ be $y$ that does $z$ ' as a mezzo rule. A mezzo rule is a rule form that operates through a particular kind of interpretive process that adds a 'deliberative distance' to other single rule forms. A mezzo rule is more than an expression of one or more of the constitutive elements of the rule system. Since it is a form of codification that facilitates fuller critical awareness of rule-following behaviour, it might be thought of as intrusive within the existing rule system at the same time as it is defining of some aspect of that rule system. It is here that the act of codification itself might intrude a kind of aporia into the rules on the basis that the terms of the rules are stated. This mezzo form encapsulates how the taxonomic range of individual rules can be recodified, creating in turn a taxonomic range of mezzo rules. For example the original form:

'In circumstance $x$ do not do $y$, do $z$ because a does $y$ '

becomes

'In circumstance $x$ do not do $y$, be $c$ that does $z$ because a does $y$ ',

37 Though this in turn invokes the homunculus fallacy: a potentially infinite series of selves observing and analysing the initial social self. This is a problem that can easily reproduce a form of the Cartesian intra-subjective approach. The problem, however, flows from a semantic confusion between individuality and autonomy. One cannot surrender the idea of the individual that is non-reducible to roles even if one resists the idea of a timeless autonomous given being. The dichotomy is in some respects false as Archer tries to show in terms of the significance of internal conversations.

38 Though the degradation may be of other sorts, such as third person legal intervention/transformation or perhaps simple unintended consequences of complexity that then change circumstance $x$ or impinge on $y$. 
Here the interpretive process of codification links being and doing, whilst the explanatory and conditional nature of the rule form invites additional interpretation of the terms of 'because'. ${ }^{39}$ Through such mezzo rules 'tends' becomes a potential aspect of the individual rule form as well as a capacity of the agent who otherwise follows rules. Choice begins to mutate into creative responses. As such, the problem of the fluidity of rules, of the practical dynamism of rule-following behaviour, and fluidity, perhaps aporia within and between rules, is potentially clarified and made more consistent with both the methodological framework of OIE and with Searle's underpinning approach to rules in relation to context, intentionality background, and so forth. ${ }^{40}$

\section{Conclusion}

The OIE is an important contribution to the plurality of approaches in economics. It is one with a great deal of scope for highlighting the broad context of the activity of economic agents. It is one that has a great deal of scope for exploring the dynamism of that activity. In this paper we have tried to clarify the concept of a single rule form in order to contribute to applications of the OIE that must confront this practical dynamism. We have argued that setting out a taxonomic range of single rule forms provides a conceptual resource for the researcher in mapping out how rules fit together into rule systems. We have argued that identifying a range of single rule forms allows us to distinguish between different characteristics of rule forms. One can, for example, usefully express negation (do not) within the rule form. One can express inter-subjectivity within the rule form. One can distinguish between multiplicity of similar rules forms - the distribution of activities - and choice. One can distinguish between regularity and choice and between choice and degrees of creative response. One can also begin to think about the fluidity of rules in a variety of compatible ways. Rules can be more or less deterministic and this can be expressed in the rule form

39 Various issues of inference and statement forms can then follow that are not themselves rule forms but are reliant on the interpretive process by which the rule form is codified. For example: 'In circumstance $x$ be $y$ that does $z$ is open for deliberative change because I/WE understand the specific mechanics of 'In circumstance $x$ be $y$ that does z.'

40 One might continue to explore a whole variety of potential mezzo rule forms here and also link these to further reconstructions of the original rule forms that agents had previously followed. One might note that the synchronic (or always and everywhere potential) for aporia in rules then expresses itself diachronically in further recodifications that follow from mezzo rule codifications. Rules then become active and fluid through time as rule-following behaviour or the practical dynamism of rules plays out. Reconstructions might diachronically include 'In circumstance $x$ do $\beta$ not $y$ ', or following recodification and the transformation of $x$ : 'In circumstance $x_{1}$ do $\beta$ not $y$ '. Here 'not $y$ ' would temporarily remain part of the rule form since $y$ was the previous action that is now rejected in favour of $\beta$ and its rejection may be part of the cognitive process of the rule-following behaviour $\beta$. As the new behaviour embeds and becomes habitual 'not $y$ ' may simply disappear if and when the rule form is once again codified because $\beta$ may no longer require the memory trace of 'not $y$ '. Unfortunately, space precludes any further development of the argument here. 
as well as in the capacity of the agent that is applied to the rule form. Mapping using a taxonomic range of rule forms might provide a practical expression of how rules fit together fluidly on the basis of their difference. Finally, one might consider the idea of fluidity in terms of mezzo rules or codifications that both define and distance the codifier from the original habit or rule form and express the fluidity of rules - perhaps through a process of deliberative degradation of the commitments inherent in the original rule form. We take these clarifications and elaborations on rules to be a positive contribution to the OIE rather than a violation of Okham's: Entia non sunt multiplicanda praetor necessitatem. ${ }^{41}$

\section{References}

Archer, M. (2007), Making Our Way Through the World: Human Reflexivity and Social Mobility, Cambridge: Cambridge University Press.

Assiter, A. (2009), Kierkegaard, Metaphysics and Political Theory, London: Continuum.

Austin, J. L. (1961), Philosophical Papers, Oxford: Oxford University Press.

Bergmann, M. (2008), An Introduction to Many-Valued and Fuzzy Logic: Semantics, Algebras and Derivation Systems, Cambridge: Cambridge University Press.

Bigo, V. and I. Negru (2008), 'From fragmentation to ontologically reflexive pluralism', The Journal of Philosophical Economics, 1(2): 127-150.

Blaug, M. (1992), The Methodology of Economics: Or How Economists Explain, second edition, Cambridge: Cambridge University Press.

Boehm, S. (2002), 'The ramifications of John Searle's social philosophy in economics', Journal of Economic Methodology, 9(1):1-10.

Bourdieu, P. (1988), Homo Academicus, Cambridge: Polity.

Bourdieu, P. and L. Wacquant (1992), An Invitation to Reflexive Sociology, Cambridge: Polity.

Buller, D. (2005), Adapting Minds: Evolutionary Psychology and the Persistent Quest for Human Nature, Boston, MA: MIT.

Chick, V. and S. Dow (2005), 'The meaning of open systems', Journal of Economic Methodology, 12(3): 363-381.

Colander, D. (2000), 'The death of neoclassical economics', Journal of the History of Economic Thought, 22(2): 127-143.

Collin, F. (1997), Social Reality, London: Routledge.

Dequech, D. (2002), "The demarcation between the "Old" and the "New" institutional economics: recent complications', Journal of Economic Issues, 36(2): 565-572.

Dewey, J. (1920/1957), The Reconstruction of Philosophy, Boston: Beacon Press.

Diamond, C. (ed.) (1976), Wittgenstein's Lectures on the Foundations of Mathematics, Cambridge, 1939, Hassocks: Harvester.

Dow, S. (2004), 'Structured pluralism', Journal of Economic Methodology, 11(3): 275-290.

Downward, P. and A. Mearman (2003), 'Critical realism and econometrics', in P. Downward (ed.), Applied Economics and the Critical Realist Critique, London: Routledge.

Fleetwod, S. (2008a), 'Structure, institution, agency, habit and reflexive deliberation', Journal of Institutional Economics, 4(2): 183-203.

41 Entities should not be multiplied beyond necessity. 
Fleetwod, S. (2008b), 'Institutions and social structures', Journal for the Theory of Social Behaviour, 38(3): 241-265.

Fullbrook, E (2004), “'Descartes” legacy: inter-subjective reality, intra-subjective theory', in J. Davis, A. Marciano, and J. Runde (eds.), Elgar Companion to Economics and Philosophy, London: Edward Elgar.

Fullbrook, E. (ed.) (2009), Ontology and Economics: Tony Lawson and his Critics, London: Routledge.

Granovetter, M. (1985), 'Economic action and social structure: the problem of embeddedness', American Journal of Sociology, 91(3): 481-510.

Harding, S. 'Rethinking standpoint epistemology: what is "strong objectivity"?', in L. Alcoff and E. Potter (eds.), Feminist Epistemologies, London: Routledge.

Harre, R. and M. Krausz (1996), Varieties of Relativism, Oxford: Blackwell.

Heilbroner, R. and W. Milberg (1995), The Crisis of Vision in Modern Economic Thought, Cambridge: Cambridge University Press.

Hodgson, G. M. (1988), Economics and Institutions: A Manifesto for a Modern Institutional Economics, Cambridge: Polity.

Hodgson, G. M. (1998), 'The approach of institutional economics', Journal of Economic Literature, 36(1): 166-192.

Hodgson, G. M. (2001), How Economics Forgot History: The Problem of Historical Specificity in Social Science, London: Routledge.

Hodgson, G. M. (2002), 'Reconstitutive downward causation: social structure and the development of individual agency', in E. Fullbrook (ed.), Inter-subjectivity in Economics: Agents and Structures, London: Routledge.

Hodgson, G. M. (2003), 'John. R. Commons and the foundations of institutional economics', Journal of Economic Issues, 37(3): 547-567.

Hodgson, G. M. (2004), The Evolution of Institutional Economics: Agency, Structure and Darwinism in American Institutionalism, London: Routledge.

Hodgson, G. M. (2006), 'What are institutions?', Journal of Economic Issues, 40(1): 1-25.

Hodgson, G. M. (2007a), 'Evolutionary and Institutional Economics as the New Mainstream?', Evolutionary and Institutional Economics, Review, 4(1): 7-25.

Hodgson, G. M. (2007b), 'The revival of Veblenian institutional economics', Journal of Economic Issues, 41(2): 325-340.

Hodgson, G. M. (ed.) (2007c), The Evolution of Economic Institutions: A Critical Reader, London: Edward Elgar.

Hollis, Martin (1996), 'How biological beasts learn the rules of the game', The Times Literary Supplement, 12 January.

Koepsell, D. and L. Moss (eds.) (2003), Searle on the Institutions of Social Reality: Extensions, Criticisms and Reconstructions, Oxford: Blackwell.

Kripke, S. (1982), Wittgenstein on Rules and Private Language, Oxford: Blackwell.

Lahno, B. (2007), 'Rational choice and rule-following behaviour', Rationality and Society, 19(4): 425-450.

Lawson, T. (1997), Economics and Reality, London: Routledge.

Lerner, M. (1948), The Portable Veblen, New York: Viking Press.

Leijonhufvud, A. (1973), 'Life among the econ', Western Economic Journal, 11(3): 327337.

Maki, U. (1993), 'Economics with institutions: agenda for methodological enquiry', in U. Maki, B. Gustaffson, and C. Knudsen (eds.) Rationality, Institutions and Economic Methodology, London: Routledge. 
Morgan, J. (2009a), 'How should we conceive the continued resilience of the US Dollar as a reserve currency?', Review of Radical Political Economics, 41(1): 43-61.

Morgan, J. (2009b), Private Equity Finance: Rise and Repercussions, Basingstoke: Palgrave Macmillan.

Morgan, J. (2009c), 'The limits of central bank policy: economic crisis and the limits of effective solutions', Cambridge Journal of Economics, 33(4): 581-608.

Mundle, C. (1971), 'Behaviourism and the private language argument', in O. Jones (ed.), The Private Language Argument, Basingstoke: MacMillan.

Neilsen, P. and J. Morgan (2005), 'No new revolution in economics?', Economy and Society, 34(1): 51-75.

Nellhaus, T. (1998), 'Signs, sociology and critical realism', Journal for the Theory of Social Behaviour, 28(1): 1-24.

Ostrom, E. (1986), 'An agenda for the study of institutions', Public Choice, 48(1): 3-25.

Parrish, J. (1967), 'Rise of economics as an academic discipline: the formative years to 1900', The Southern Economic Journal, 34(1): 1-16.

Pawson, R. and N. Tilley (1997), Realistic Evaluation, London: Sage.

Peirce, C. S. (1974), Collected Papers Of Charles Sanders Peirce: Volume 1, Cambridge MA: Bellknap, Harvard University Press.

Perraton, J. and I. Tarrant (2007), 'What does tacit knowledge actually explain?', Journal of Economic Methodology, 14(3): 353-370.

Polanyi, M. (1962/1998), Personal Knowledge: Towards a Post-critical Philosophy, London: Routledge.

Rabin, M. (1993), 'Incorporating fairness into Game Theory And Economics', American Economic Review, 83(5): 1281-1301.

Ransdell, J. (1971), 'Constitutive rules and speech act analysis', Journal of Philosophy, 68(13): $385-400$.

Ruben, D.-H. (1997), 'John Searle's Construction of Social Reality', Philosophy and Phenomenological Research, 57(2): 443-447.

Runde, J. (2002), 'Filling in the Background', Journal of Economic Methodology, 9(1): 11-30.

Rust, J. (2006), John Searle and the Construction of Social Reality, London: Continuum.

Santos, A. (2009), 'Behavioural experiments: how and what we can learn about human behaviour', Journal of Economic Methodology, 16(1): 77-88.

Schumpeter, Joseph (1997), History of Economic Analysis, London: Routledge.

Searle, J. (1969), Speech Acts, Cambridge: Cambridge University Press.

Searle, J. (1995), The Construction of Social Reality, London: Penguin.

Searle, J. (1999), Mind, Language and Society, London: Phoenix.

Tilman, R. (2007), Thorstein Veblen and the Enrichment of Evolutionary Naturalism, Columbia, MI: University of Missouri Press.

Tuomela, R. (1997), 'Searle on social institutions', Philosophy and Phenomenological Research, 57(2): 435-441.

Vanberg, V. (2007), Rational Choice, Preferences Over Actions and Rule-Following Behaviour, Freiburg Discussion Papers on Constitutional Economics, Freiburg: WalterEuken Inst.

Veblen, T. (1914/2006), The Instinct of Workmanship and the State of the Industrial Arts, Cosimo Classics Series, New York: Cosimo, Inc.

Wittgenstein, L. (1953/1997), Philosophical Investigations, Oxford: Blackwell. 